\title{
Designing for surface water runoff control: end-user requirements in Ireland
}

\author{
M. Bruen, J. J. O'Sullivan, F. A. Gebre, and P. J. Purcell \\ Centre for Water Resources Research, University College, Belfield, Dublin 4, Ireland \\ Received: 7 December 2007 - Revised: 19 May 2008 - Accepted: 28 May 2008 - Published: 4 July 2008
}

\begin{abstract}
Since 1975, flood estimation in Ireland has generally followed methods as outlined in the Flood Studies Report (Natural Environment Research Council, 1975). An update of this for conditions in the Republic of Ireland commenced in 2005 and included research in Urban Catchment Flood Analysis. To inform this work, a scoping study of issues relating to flooding caused by urban runoff was undertaken by a team from the Centre for Water Resources Research at University College Dublin and some of the findings are described in this paper. It focussed on quantitative and qualitative research methods (self-completion questionnaires and Focus Groups) to review the methods of flood estimation for urbanised catchments currently in use in Ireland. It assessed the nature of deficiencies associated with urban-runoff control and identified achievable and realistic objectives for further research. A questionnaire was developed around a number of key themes pertaining to flooding caused by urban runoff and circulated to 291 stakeholders in target sectors that ranged from Engineering Consultancies to Academic Institutions. A total of 100 questionnaires were returned giving a $34 \%$ response rate. The study found; (i) a proliferation of methods are used in practice resulting in significant differences between the estimates; (ii) some methods are sometimes being used for inappropriate spatial scales; (iii) there is a lack of clear guidance on the use of the methods and/or associated software packages; (iv) there is little appreciation of the uncertainties associated with the methods and (v) there are significant deficiencies in some of the basic information available.
\end{abstract}

A list of recommendations was produced, to guide the commissioning of future research to improve the methods available to designers.

Correspondence to: $\mathrm{M}$. Bruen

(michael.bruen@ucd.ie)

\section{Introduction}

Flood estimation in Ireland currently follows methods outlined in the 1975 Flood Studies Report (FSR) (Natural Environment Research Council, 1975) and the numerous Flood Studies Supplementary Reports that followed. The FSR was superseded in the United Kingdom by the Flood Estimation Handbook (FEH) (Institute of Hydrology, 1999). Ireland's Office of Public Works (OPW) is the Government's lead agency for flood risk management. However, it was not involved in developing the Flood Estimation Handbook and consequently, the method was not developed for, nor does it represent, the hydrology of catchments in the Irish Republic. In the context of increased urbanisation in Irish catchments and the impact of global climate change on the natural hydrology of catchments, the OPW initiated a review and update of the 1975 FSR for Ireland. A primary objective was to avail of the hydrometric data that has been recorded in the period since the FSR and to utilise advances in computer and digital technologies to provide the engineering community with improved methods of rainfall and flood estimation. As part of this update, the authors undertook a scoping study of issues related to flooding caused by urban runoff in Ireland and assessed the methods used and problems experienced by practitioners in the area.

\section{Context}

Ireland has experienced an upsurge in the development of residential, commercial and industrial properties in the last decade. Improvements in transportation initially encouraged the dispersal of significant populations to the outskirts, and beyond, of urban areas. This has resulted in continued expansion of urban belts around the country where the outer fringes of towns and cities have increasingly become transition zones linking adjacent centres of population. Furthermore, the

Published by Copernicus Publications on behalf of the European Geosciences Union. 
National Spatial Strategy for Ireland from 2002 to 2020 (National Spatial Strategy, 2002) recommends a balanced approach to social, economic and physical development between regions. It has identified towns and cities that have the potential to be renewed and developed. A significant number of these "renewable" areas that have been identified for further development are located along river corridors or in floodplains. There are both (i) historical reasons for this, related to the development of towns and cities at locations where the river could be easily crossed and (ii) modern reasons, related to the comparatively low price and availability of floodplain land adjacent to rivers and subject to flooding.

\section{Aims of study}

This paper reports some of the results of a scoping study that reviewed issues related to floods caused by urban runoff in Ireland. It includes:

1. Reviewing the methods of urban catchment flood analysis currently in general use in Ireland;

2. Reviewing the status of these and other methods with regard to software provision and the scientific and legal supportability of the methods;

3. Recommending items of Research and Development with the capability of delivering improved and generally applicable methods of urban runoff flood analysis.

These objectives were addressed by means of both quantitative and qualitative research.

\subsection{Quantitative research}

A questionnaire was sent to targeted stakeholders in relevant sectors with the objective of generating both baseline and detailed information on currently used approaches to estimating and managing floods caused by urban runoff. The target sectors that were identified for this work-package are summarised as:

- Engineering consultants

- Engineering contractors

- Architects / landscape architects

- Local Authorities, including; County Councils; City and Town Councils and the City Councils of Dublin Cork and Galway

- Academics.

The questionnaire was structured around eight themes as follows:
- Introduction

- General information

- Implications of urbanisation

- Peak flow estimation in greenfield catchments

- Peak flow estimation in urban catchments

- Guidelines for peak flow estimation in greenfield and urban catchments

- Design and modelling of stormwater drainage systems

- Stormwater management.

\subsection{Qualitative research}

The qualitative element of the research involved Focus Groups that concentrated on specific issues identified in the questionnaire survey that were of particular concern to practitioners of urban hydrology in Ireland. Four lunchtime Focus Group meetings were held in three locations. In keeping with the project brief where the requirement for the scoping study to review flood issues across Ireland is recognised, Focus Groups involving a total of 24 participants, were held in the major conurbations of Dublin (2 groups), Cork and Galway.

A total of 291 questionnaires were circulated, both electronically and by post and the response rate was $34 \%$. A large majority of the questionnaires returned ( 82 out of a total of 100 responses) were from engineering consultancies and public bodies (Local Authorities, County Councils, City Councils etc.) indicating that these organisations lead in the design, planning and implementation of all aspects that relate to flooding due to urban runoff. The responses suggest that currently, engineering contractors, architects and planners seem to have little or no involvement in this area. This is of concern because it indicates weakness in the connection between floods and (i) the planning of urban developments (planners); (ii) the flood-proofing of buildings (architects) and (iii) specific flood vulnerabilities during construction (contractors).

\section{Results and analysis}

4.1 Equations/methods used in determining peak flows from greenfield sites

Respondents were asked to state the methods for calculating design flood peaks from greenfield sites with which they were most familiar. A list of commonly used methods was provided in the questionnaire. The responses are shown in Table 1. 
Table 1. Percentage of respondents familiar with Equations/Methods used for estimating peak flows from greenfield catchments.

\begin{tabular}{lc}
\hline Method / Equation & \% Respondents \\
\hline Institute of Hydrology / Report no. 124 & 21.5 \\
Rational Method & 19.5 \\
Prescribed runoff rate & 9.0 \\
Unit Hydrograph methods & 9.0 \\
FSR Supplementary Report no. 6 (3var & 9.0 \\
eqn.) & \\
FSR - 6-var. eqn & 8.0 \\
FSR - 3-var Eqn. & 6.5 \\
Flood peak frequency analysis & 5.5 \\
ADAS Report no. 5 (MAFF, 1980) & 4.5 \\
Unspecified / other & 3.5 \\
FSR 2-var Equation & 2.5 \\
FSR 1-var Equation & 1.5 \\
\hline
\end{tabular}

The equation recommended by the Institute of Hydrology (IoH) Report No. 124 (Institute of Hydrology, 1994) and the Rational Method are the most common methods, with $21.5 \%$ and $19.5 \%$ of respondents using these approaches. This perhaps reflects the respondent's familiarity with the Dublin City Council - Stormwater Management Policy for Developers (Dublin City Council, 1998), which recommends the use of the IoH method for catchments of up to 24 hectares in area. The Unit Hydrograph approach, the Flood Studies Report (Natural Environment Research Council, 1975) 6-Variable and 3-Variable equations and the Flood Studies Supplementary Report No. 6 (Natural Environment Research Council, 1978) 3-Variable equation are also well represented.

In addition to the results in Table 1, some respondents also mention using the Flood Estimation Handbook (Institute of Hydrology, 1999) and the Transport and Road Research Laboratory Report No. 565 (TRRL, 1973) as methods for estimating peak flows from natural catchments. A catchment area ratio method, SMARG (NUI Galway software) (O'Connor et al., 2001) and the Topkapi (Liu and Todini, 2002) physically based and fully distributed hydrological modelling system were also included in responses.

Respondents were asked to identify the main difficulties/limitations they experienced when using these methods. The most common responses were grouped and are summarised in Table 2. These tended to be general and rather sweeping in their nature. It is clear that respondents are aware that uncertainties exist in the application of the various peak flow estimation methods for urban catchments but evidence of a deeper understanding of where these uncertainties may originate is not so apparent. This is important since, even though a particular equation may give the best estimate of a flood peak of a required return period, if there is a large uncertainty in this "best" estimate, then a greater discharge
Table 2. Main difficulties/limitations identified by respondents when calculating design flood peaks for greenfield catchments.

\begin{tabular}{lc}
\hline Difficulty & \% Respondents \\
\hline $\begin{array}{l}\text { Lack of confidence in the methods/too } \\
\text { many assumptions }\end{array}$ & 31.3 \\
$\begin{array}{l}\text { Concerns about the accuracy of data } \\
\text { (particularly for rainfall and soils) }\end{array}$ & 22.9 \\
$\begin{array}{l}\text { Methods perceived to be too simple for } \\
\text { large catchments }\end{array}$ & 12.5 \\
$\begin{array}{l}\text { Lack of sufficient spatial detail in data } \\
\text { Difficulties in getting appropriate soil } \\
\text { and rainfall data }\end{array}$ & 10.4 \\
$\begin{array}{l}\text { Inadequate guidance about methods } \\
\text { and associated software }\end{array}$ & 6.3 \\
$\begin{array}{l}\text { Method considered inappropriate/ } \\
\text { i.e. FSR does reflect Irish conditions }\end{array}$ & 2.3 \\
Other & 10.4 \\
\hline
\end{tabular}

capacity must be provided in a design to reduce to acceptable levels the probability of its capacity being exceeded. Significant under-design can occur if this uncertainty is not taken into account.

The main difficulty identified by over $31 \%$ of respondents was the inconsistency in the values of the peak flow determined from the various methods and how these varied over catchments of different sizes. It was noted that some of the commonly applied methods overestimate design flows, imposing extra costs on developers for attenuation structures. The manner in which the runoff behaviour is influenced both by the hydraulic properties of the soil and by land use was considered to be oversimplified in many of the methodologies.

Another major problem, identified by almost $23 \%$ of respondents was the accuracy, resolution and validity of the data on which the methodologies are based. Some of the required variables used in the Flood Studies Report (Natural Environment Research Council, 1975), e.g. SOIL, SAAR, runoff coefficients, concentration times, are not site specific and can vary widely. Interpolation, where required, of hydrological parameters is subjective and open to question. In addition, the soil parameters do not account for site topography or slope. The issue of poor quality data was flagged, particularly relating to how the effect of soil type and properties are taken into account, and was further addressed in the Focus Group meetings. The Focus groups considered that "it would be very good to get site specific data". However, concerns were also raised about the perceived cost and the time implications of imposing obligatory soil tests on developers.

Similar issues relating specifically to soil index estimation, catchment delineation and poor map resolution were mentioned by an additional $10 \%$ of respondents and these are consistent with the data quality issue already discussed. In 


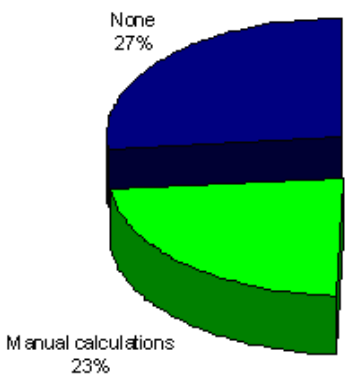

$23 \%$

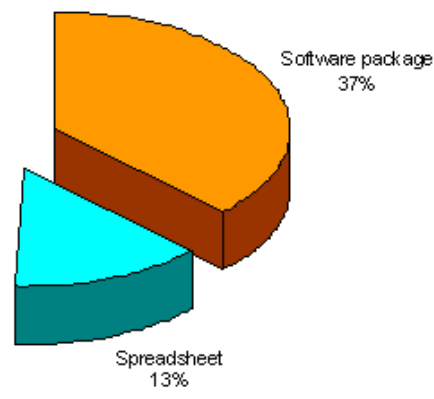

Fig. 1. Approach to design of stormwater drainage systems adopted by respondents.

addition to the above responses, about $6 \%$ of respondents have concerns over access to or availability of data including rainfall, flow and soil type. It was noted that at times in the past, rainfall and river monitoring equipment had fallen into disrepair and significant time periods had elapsed before these devices were operating.

Another 4\% have identified the lack of national guidance governing "best approaches" to the problem of runoff estimation from greenfield sites. These were supported by Focus group comments;

"There should be a recognised small catchment approach and a big catchment approach"

and

"I know I'm only involved in road design, but I'd be looking for a procedure for greenfield sites. I'd need a set of steps. At the moment, it's grey (a grey area) on what you do or don't need to design for".

The majority of the difficulties/limitations were raised by engineering consultants. However, County Council and Local Authority representatives also contributed.

The following more general comments were also made:

- Guidelines are sometimes too general

- Most methods are strictly applicable to large catchments

- The linear relationship for scaling catchments inherent in some estimation methodologies is questionable

- Uncertainties in defining the extent of urban areas within catchments can induce uncertainty in flood estimates

- Data and information on which flood estimates are based is outdated

- There is no agreed structure between practitioners for flood estimation and this results in a lack of consistency

- Peak flows estimated from various methods are subjective and are often very conservative.
Table 3. Approaches to stormwater system design by target sector (by number of citations).

\begin{tabular}{|c|c|c|c|c|}
\hline Organisation type & $\begin{array}{l}\text { Software } \\
\text { pack- } \\
\text { age }\end{array}$ & $\begin{array}{l}\text { Spread- } \\
\text { sheet }\end{array}$ & $\begin{array}{l}\text { Manual } \\
\text { calcs. }\end{array}$ & None \\
\hline Contractor/Builder/Developer & 1 & - & 1 & 4 \\
\hline Consultant & 22 & 6 & 4 & 2 \\
\hline $\begin{array}{l}\text { Public (Council, LA, Aca- } \\
\text { demic, ...) }\end{array}$ & 5 & 3 & 12 & 12 \\
\hline Insurance & - & 1 & - & - \\
\hline $\begin{array}{l}\text { Architects/Planners/Urban } \\
\text { Designer }\end{array}$ & - & - & - & 2 \\
\hline Total & 28 & 10 & 17 & 20 \\
\hline
\end{tabular}

\section{Design and modelling of stormwater drainage sys- tems}

\subsection{Approach to stormwater management}

Respondents were asked to specify the methods they used in designing stormwater systems. A total of $37 \%$ of the survey sample utilise various software packages when designing drainage systems with manual and spreadsheet calculation methodologies accounting for the other approaches identified. The breakdown of methods is shown in Figure 1. A significant proportion of the $27 \%$ of respondents who do not use any prescribed methods in the design of stormwater systems were from the County Council and Local Authority target sectors. Furthermore, Table 3 shows the various approaches to storm-water system design by target sector, and representatives in these target sectors also rely more heavily on manual calculations for design purposes than engineering consultants. This suggests that the role of practitioners in organisations of this type is not primarily a design role, at least not on a day to day basis, but may involve checking design values submitted by engineering consultants.

In a further question, respondents were asked to state the main difficulties/limitations that they had experienced when using software packages. The main limitations that were identified were arranged in seven groupings and are shown in Table 4.

In addition to the responses in Table 4, some respondents noted the poor quality of information about existing drainage infrastructure.

\section{Recommendations from respondents}

It is clear that peak flow estimation from urban catchments is usually undertaken using the Rational or a related method, often incorporated into a computer model of the hydraulic collection system for larger catchments. The main difficulties experienced by users related to the estimation of the "nat- 
ural", pre-development, flood peak for greenfield or partially urbanised catchments. Some specific issues and recommendations are as follows;

\section{Estimating hydrological capacity with new Irish soil maps}

New soil maps have been compiled by Teagasc, the Irish Agriculture Research organisation, for the 26 counties of the Irish Republic. They classify Irish soils in terms of 44 associations, each association being a proportioned composite of other soil types. It is recommended that further work should be undertaken to investigate whether any consistent relationships between these new soil maps and rainfall-runoff coefficients and concentration times can be established. Some work (unreported) has already begun in using soil type as one of the factors in estimating flow-duration curves for ungauged catchments in the context of the Water Framework Directive, however the main focus is on low flows.

\section{Site specific characterisation studies}

Rather than depend completely on the mapped hydraulic capacities, there could be some attempt made to determine site specific values. A suite of simple tests (quick and cheap) should be developed that can be used to characterise the runoff behaviour of individual sites. For instance, Teagasc (the Irish Agriculture Research organisation), in combination with all Local Authorities, have at their disposal a large body of soil percolation test results that would have accompanied planning applications for developments that included, for example, septic tanks. In such tests, the time taken for a given volume of water to soak from a hole of a specified size is recorded. This data is currently not available on any database that could assist Irish hydrologists. The authors are aware that from a catchment analysis perspective, such percolation test results will apply only to the ground level layers at a localised point in a catchment and will therefore not represent catchment infiltration. However, whenever the only alternative is mapped values, the authors feel that merit exists in examining percolation values for a range of catchment types to investigate the relationship, if any, that may exist between percolation, infiltration and runoff generation.

If relationships are shown to exist between percolation and infiltration, scope exists for collating all percolation values into a GIS based national database that could be continuously updated by the results of new tests.

\section{Validation of hydraulic modelling approaches}

Participants in this scoping review provided information on a number of software packages that are commonly used to support stormwater system design and analysis. While it was accepted that the technical support for these software packages when applied to Irish catchments was generally deficient, little comment was made on the perceived accuracy and variability of the general modelling approach. Previous research,
Table 4. Main difficulties/limitations in using listed software packages).

\begin{tabular}{lc}
\hline Difficulty & \% Respondents \\
\hline $\begin{array}{l}\text { Some computer programmes can't } \\
\text { model streams, inverted siphons, can be }\end{array}$ & 26.1 \\
tedious to use and tend to overestimate & \\
Lack of technical/guidance documenta- & 17.4 \\
tion & \\
Lack of experience / need for training & 17.4 \\
Some packages work better for the UK & 13.0 \\
and not so well for Ireland & \\
SUDS not adequately modelled & 8.7 \\
More suitable for pipe networks only & 8.7 \\
Potential for error in "home-grown" & 8.7 \\
spreadsheets & \\
\hline
\end{tabular}

undertaken at CWRR identified significant differences between measured and modelled floods, both in the magnitude and timing of flood peaks (Bruen and Yang, 2006). Thus, research should be undertaken to validate these modelling approaches for Irish catchments to assess the magnitude and sources of errors (including deficiencies in the description of the hydraulic network), the dependency of these errors on the input parameters and the sensitivity of the design floods to these errors. Assessing the deficiencies in descriptions of hydraulic networks may require investigation of as-built drawings.

Design implications of spatial progression of urban runoff floods

In designing flood protection and management strategies for major urban areas it is important that the dynamics of the build-up, progression and recession of the flood be understood. For instance, access of emergency services vehicles to affected areas can depend on the periods for which specific depths of water are exceeded. There is a need for guidance on methodologies to model the spatial progression for specified flooding scenarios. This would support the flood management initiatives advocated in the report of the Flood Policy Review Group (Flood Studies Review Group, 2004).

\section{Flood warning systems}

Current international practices involve the integration of flood defences with non-structural management strategies. Adequate flood warning systems are a necessary component of such integrated approaches to flood management. Irish practice is moving in this direction. This is especially important in urban areas, where lag-times are short and where the potential for damage and injury is high. 


\section{Educational needs}

A deficit exists between the actual and what would be perceived to be an acceptable level of understanding of urban catchment flood issues and in particular, in the manner in which flow estimation methodologies are applied to these catchments. It would appear that this is done on a "one size fits all" or "black box" basis where methods are applied on a prescriptive basis without due consideration being paid to the catchment characteristics that influence the rainfall-runoff process. The over-reliance on spreadsheet calculations and software packages does not necessarily help in this regard.

\section{Conclusions}

A comprehensive questionnaire study was carried out of professionals involved in the provision of measures to deal with floods generated from urban runoff. The study found

- A proliferation of methods used in practice and significant differences between the estimates. This was compounded by some of the methods sometimes being used for inappropriate spatial scales.

- Lack of clear guidance on the use of the methods and/or associated software packages.

- Little appreciation of the uncertainties associated with the methods.

- Significant deficiencies in some of the basic information available, particularly soils information.

A list of recommendations was produced in Sect. 6 to guide the commissioning of future research to improve the methods available to designers.
Acknowledgements. The authors wish to acknowledge the financial support made available by the OPW for undertaking this research. The project benefited from the careful review of their Steering Committee.

Edited by: A. M. Rossa

Reviewed by: J. Martin and another anonymous referee

\section{References}

Bruen, M. and Yang, J.: Improving the performance of hydraulic models for urban stormwater drainage systems, using simple black box models, J. Hydrologic Engineering, ASCE, 11(6), 589-596, 2006.

Dublin City Council: Stormwater Management Policy for developers, Dublin City Council, Dublin, 1998.

Flood Policy Review Group: Report of the Flood Policy Review Group, Office of Public Works, Dublin, 2004.

Institute of Hydrology: Flood estimation for small catchments, report no. 124, June 1994, Wallingford, UK, 1994.

Institute of Hydrology (IH): Flood Estimation Handbook. Institute of Hydrology, Wallingford, UK, 1999.

Liu, Z. and Todini, E.: Towards a comprehensive physically-based rainfallrunoff model, Hydrology and Earth System Sciences, 6, 859-881, in: Hydrologic and hydraulic modeling, edited by: Maidment, D. and Djokic, D., 2002.

MAFF: Pipe size design for field drainage, Report No. 5, Ministry of Agriculture Forestry and Food, UK, Dec, 1980.

Government Publications(2002): National Spatial Strategy for Ireland, 2002-2020, Government Publications, Dublin.

Natural Environment Research Council: Flood Studies Report. HMSO, London, 1975.

Natural Environment Research Council: Flood prediction for small catchments, Flood Studies Supplementary Report No. 6. HMSO, UK, 1978.

O’Connor, K. M., Goswami, M., Liang, G. C., Kachroo, R. K., and Shamseldin, A. Y.: The development of the Galway real-time river flow modelling and forecasting system (GFMFS), in The proceedings of the 19th European Regional Conference of ICID, 2001.

TRRL: Estimation of Flood flows from natural catchments, Transport and Road Research Laboratory Report no. 565 edited by: Young, C. P. and Prudhoe, J., TRL, UK, 1973. 